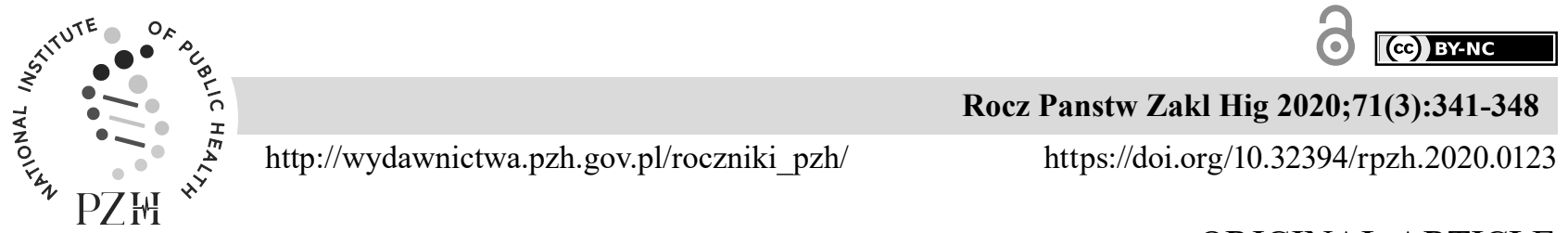

ORIGINAL ARTICLE

\title{
RELATIONSHIP BETWEEN FARMERS' KNOWLEDGE AND ATTITUDES TOWARDS PESTICIDE USE AND THEIR SOCIODEMOGRAPHIC CHARACTERISTICS: A CROSS-SECTIONAL STUDY FROM NORTHWESTERN TURKEY
}

\author{
Celalettin Cevik', Raziye Ozdemir ${ }^{2}$, Sezgin Ari ${ }^{3}$
}

${ }^{1}$ Balikesir University, Faculty of Health Sciences, Department of Public Health Nursing, Balikesir, Turkey ${ }^{2}$ Karabuk University Health Sciences Faculty, Midwifery Department, Demir Çelik Campus, Karabuk, Turkey ${ }^{3}$ Balikesir University, Faculty of Health Sciences, Department of Nursing, Balikesir, Turkey

\begin{abstract}
Background. The determination of farmers' knowledge and attitudes towards pesticide use is very important in terms of preventing pesticide use-related short- and long-term damages.

Objective. This study was aimed at investigating the relationship between the sociodemographic characteristics of farmers in Karacabey District of Bursa, a province in northwest Turkey, and their knowledge and attitudes towards pesticide use. Material and methods. This cross-sectional study was conducted in Karacabey district between December 2018 and April 2019. The sample size was calculated as 1924 using the Epi info program by assuming the prevalence as 50\%, type I error as $5 \%$, standard deviation as $3 \%$ and design effect as 2 . The dependent variable of the study was the farmers' knowledge of and attitudes towards pesticide use whereas the independent variables were their sociodemographic characteristics. The relationship between the dependent and independent variables was analyzed using the chi-square test and binary logistic regression model.

Results. The mean score the participants obtained from the Knowledge and Attitude Index was $12.8 \pm 2.8$ and the median value was 13 . While $49.5 \%$ of the participating farmers obtained a score lower than the median, $51.5 \%$ of them obtained a score equal to or above the median. While advanced age increased the possibility of getting a low score from the Knowledge and Attitude Index 2.7 times, not being married increased it 35.7 times, not getting formal education increased it 30.1 times, living in a non-crowded household increased it 2.1 times, and low income (2000 Turkish liras equal to $\leq \$ 310$ according to April 2019 exchange rates) increased it 3.1 times.

Conclusion. The study indicated that the participating farmers' knowledge and attitudes towards the proper use of pesticides were inadequate, and that there was a strong relationship between their Knowledge and Attitude Index scores and their sociodemographic characteristics.
\end{abstract}

Key words: pesticide, knowledge, attitude, sociodemographic characteristics, public health

\section{INTRODUCTION}

Excessive, illogical and unconscious use of pesticides which have been widely used in agricultural activities since the early $1970 \mathrm{~s},[6,13]$ is an important public health problem threatening human and environmental health [13]. The fact that the number of people working in agriculture is high all over the world but in particular in developing countries places the pesticide use-related short- and long-term damage at the forefront of the current agenda as a serious problem [5, 17, 25, 31]. According to United Nations
(UN), an average of about 200,000 people die from the toxic exposure of pesticides per year across the World [15]. Pesticides also create a serious burden of disease (The disability-adjusted life-year (DALY) in many countries, especially in developing countries [16]. In addition, the use of highly toxic pesticides, forbidden in developed countries, is widespread in developing countries, which increases the risk of pesticide-related deaths in those countries [22]. Due to factors such as unnecessary use of pesticides [1], inappropriate use of pesticides [3, 4, 7, 8, 22], not using or misusing protective equipment [3], due to lack of knowledge

Corresponding author: Assoc. Prof. Celalettin Cevik (ORC-ID: 0000-0002-1123-6196), Balikesir University, Faculty of Health Sciences, Department of Public Health Nursing, Balikesir, Turkey, phone: +90 544 3928349, Fax: +90 2662440010 e-mail: celalettincevik@balikesir.edu.tr 
/ attitude, farmers face serious health problems [8, $13,21]$. Since farmers who do not have the accurate knowledge of pesticide use and display poor attitudes towards it are in an at-risk group [3], it is important to identify their knowledge / attitude levels and determinants of these low levels in order to clarify the situation and to guide public health interventions.

In the literature, according to studies conducted to investigate farmers' knowledge and attitudes towards pesticide use, the rate of farmers whose knowledge / attitude level is considered as sufficient ranges between $34 \%$ and $85 \%$ [3, 7, 17, 18, 19, 27, 28, 29]. As is reported in the literature, knowledge / attitude score is affected by factors such as age [28], income level [28], total length of time spent in farming [29], educational status [26, 27, 29] and cultural characteristics [33]. In Turkey, approximately one-fifth of the labor force, most of whom are men, is employed in agriculture [30]. In Turkey, the number of population-based studies designed to assess farmers' knowledge and attitudes towards pesticides is very limited and the samples of the available studies include a small number of farmers [7, 21].

In the present study conducted in Karacabey District of Bursa, a province in northwest Turkey, it was aimed to investigate the relationship between the sociodemographic characteristics of farmers who were registered in the Chamber of Agriculture and their knowledge and attitudes towards pesticide use. To our current knowledge, our study is the first study conducted on this issue in this region.

\section{MATERIALS AND METHODS}

This cross-sectional study was carried out within the scope of the Balikesir University scientific research project titled "Determination of farmers' knowledge and attitudes and behaviors towards pesticide use" (BAUN BAP No: 2018/169). This project has three stages: The first stage is the assessment of the knowledge and attitudes of the farmers registered in the Chamber of Agriculture in Karacabey District regarding the use of pesticides. The second stage is the determination of the behavioral characteristics of farmers who use pesticides during agricultural activities and actively work in the spraying of pesticides, and the frequency of pesticide poisoning. The third stage is the provision of training on the health effects of pesticides and ways of protection against the harmful effects of pesticides. In this study, the findings obtained from the first stage of the project are presented. The study was carried out in Karacabey district of Bursa between December 2018 and April 2019. Karacabey is a district with a population of 89,000 people. The district has three million decares (about 741316 acres) of fertile land where vegetables and fruits are intensively cultivated [10] (Figure 1).

The population of the study comprised 9750 people registered in Karacabey Chamber of Agriculture. The sample size was calculated as 1924 using the Epiinfo Statcalc Program by assuming the prevalence as $50 \%$, type I error as $5 \%$, standard deviation as $3 \%$ and design effect as 2. During the study, 2100 people were reached using the multi-stage sampling method. In the

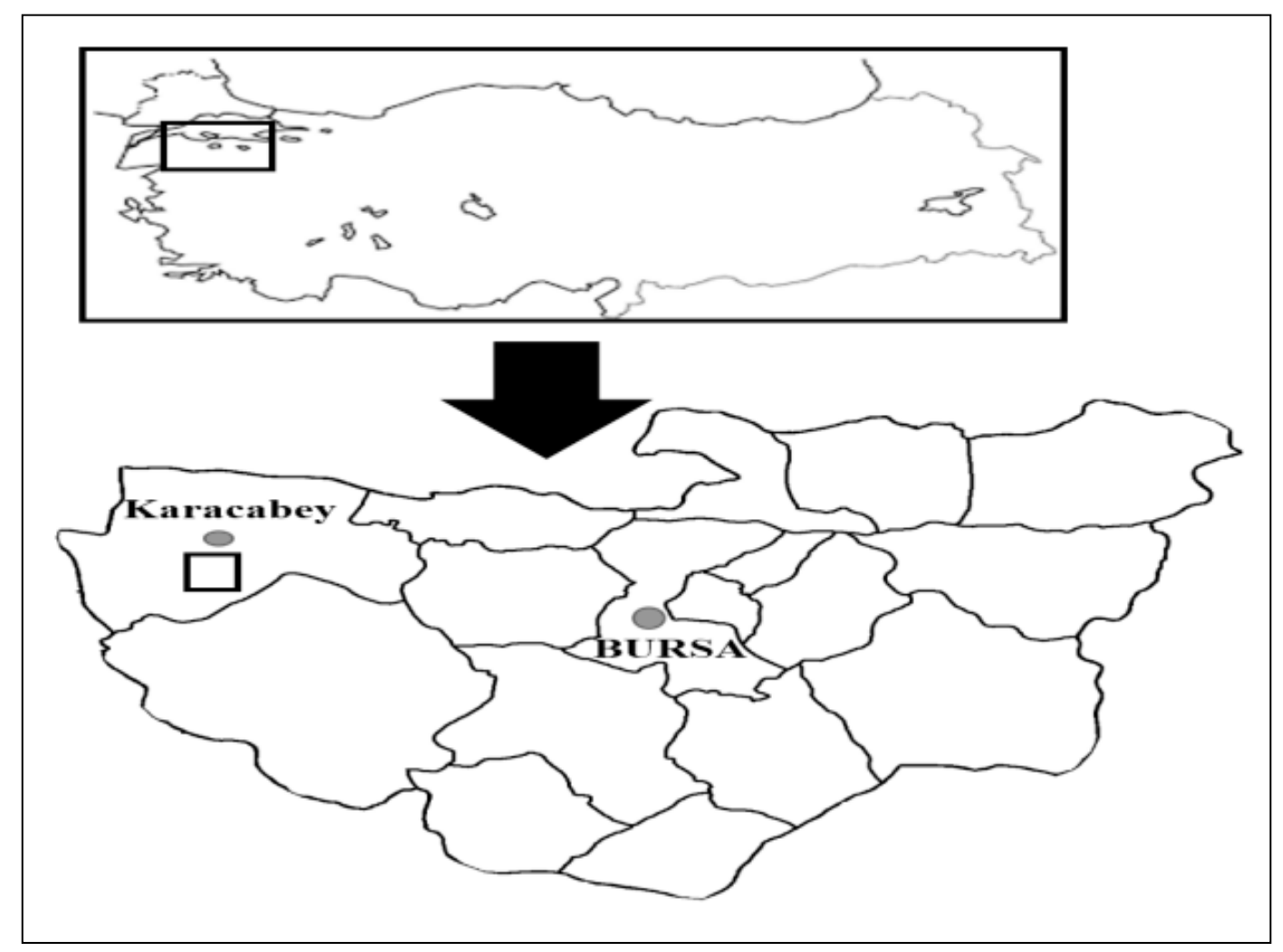

Figure 1. Study area representing Karacabey, in Turkey. 
study, firstly, the neighborhoods where the farmers registered in the Karacabey Chamber of Agriculture lived were determined. Each of the 85 neighborhoods in Karacabey district was considered as a cluster. The number of farmers targeted to be reached in each cluster was determined in proportion to the farmer population in the neighborhood. Interviews were started from the first house in each cluster and continued by skipping the second house and visiting the third house in a row. If there was no farmer in the house, then the household in the next house was interviewed.

The dependent variable of the study was the participating farmers' knowledge of and attitudes towards pesticide use score. The score was determined using the Knowledge and Attitude Index developed by the researchers based on the pertinent literature $[3,8$, $14,17,29]$. The independent variables of the study were the place of residence, age, marital status, educational status, the number of households, monthly income and total length of time spent in farming. The study data were collected using the Personal Information Form and the Knowledge and Attitude Index.

Personal Information Form: The form developed by the researchers based on the literature consists of 7 items that question the participants' sociodemographic characteristics (age, marital status, education etc.) [19, 24, 32].

The Knowledge and Attitude Index: Included 22 items questioning the participants' knowledge and attitudes regarding the effects of pesticides on human and environmental health, pesticide selection, pesticide application time, use of protective equipment during spraying, smoking status, hand washing and taking a shower after spraying, how to dispose of empty pesticide boxes. Responses included three options: "yes", "no" and "I don't know". While responses indicating that the participant's knowledge and attitudes were correct were given " 1 point", responses indicating that the participant's knowledge and attitudes were incorrect were given " 0 points". If the participant selected the "I don't know" option, "0 points" were given too. Therefore, the highest and lowest possible scores that can be obtained from the index were 22 and 0 respectively. After the scores obtained by the farmers were calculated, then the median value which was used as the cutoff point was determined. While the scores below the median value indicated that the knowledge and attitude levels were "low", the scores equal to or higher than the median value indicated that the levels were "high". The Knowledge and Attitude Index used in the study was administered to 10 farmers who were not included in the study sample for pilot testing, and then the necessary revisions were made in the index.

The data obtained in the study were summarized as percentage distribution. The relationship between the dependent and independent variables was analyzed in the SPSS 25.0 program using the chi-square test and binary logistic regression model. P-values less than 0.05 were considered statistically significant.

Ethical approval was obtained from the Ethics Committee of Balikesir University (Dated April 04, 2018, Numbered 2018/73). The farmers to participate in the study gave their verbal consent indicating that they volunteered to participate in the study.

\section{RESULTS}

Within the scope of the study, 2100 farmers were reached. All the participating farmers were vegetable and fruit growers, and applied pesticides to their crops. Of the participating farmers, $78.5 \%$ lived in a village. $24.1 \%$ were $\geq 55$ years old, $3.4 \%$ were single, $14.1 \%$ did not have any formal education. $15.9 \%$ earned more than 2000 Turkish liras (\$357 according to April 2019). exchange rates) per month and $43.9 \%$ had been engaged in farming for more than 20 years (Table 1).

Table 1. Sociodemographic characteristics of the participating farmers

\begin{tabular}{|c|c|c|}
\hline Variables & $\mathrm{n}$ & $\%$ \\
\hline \multicolumn{3}{|l|}{ Place of residence } \\
\hline District center & 451 & 21.5 \\
\hline Village & 1649 & 78.5 \\
\hline \multicolumn{3}{|l|}{ Age } \\
\hline$\leq 44$ years & 378 & 18.0 \\
\hline $45-54$ years & 1215 & 57.9 \\
\hline$\geq 55$ years & 507 & 24.1 \\
\hline \multicolumn{3}{|l|}{ Marital status } \\
\hline Married & 2028 & 96.6 \\
\hline Single & 72 & 3.4 \\
\hline \multicolumn{3}{|l|}{ Education level } \\
\hline No formal education & 298 & 14.1 \\
\hline Primary school & 1020 & 48.6 \\
\hline Junior High School & 644 & 30.7 \\
\hline Senior High school & 138 & 6.6 \\
\hline \multicolumn{3}{|l|}{ Family size (n) } \\
\hline$\leq 4$ people & 1277 & 60.8 \\
\hline$\geq 5$ people & 823 & 39.2 \\
\hline \multicolumn{3}{|l|}{ Income per month (USD)* } \\
\hline$\leq \$ 357$ & 1766 & 84.1 \\
\hline$>\$ 357$ & 334 & 15.9 \\
\hline \multicolumn{3}{|c|}{ Total length of time spent in farming } \\
\hline$\leq 20$ years & 1179 & 56.1 \\
\hline$>20$ years & 921 & 43.9 \\
\hline Total & 2100 & 100.0 \\
\hline
\end{tabular}

*\$1 = 5.74 Turkish Liras according to April 2019 exchange rates 
While a great majority of the farmers (86.8\%) stated that pesticides would increase productivity in agriculture, $22.0 \%$ stated that pesticides were harmful to human health and $83.0 \%$ said that cheaper pesticides should be preferred more. A very small number of the farmers thought that protective clothing such as masks and special overalls should be worn during the application of pesticides. While $62.0 \%$ of the farmers stated that empty pesticide containers should be buried in the ground, $57.9 \%$ of them stated that the containers might be left in the environment, $35.1 \%$ of them said that the containers should be left in outdoor garbage cans (Table 2).

The minimum and maximum scores the participating farmers obtained from the Knowledge and Attitude Index were 4 and 19 respectively. While the mean scores the participants obtained from the Knowledge and Attitude Index was $12.8 \pm 2.8$ (min: 4 max: 19), the median value was 13 . As is seen in table 3 , of the participating farmers, $49.5 \%$ obtained a score lower than the median value, and $51.5 \%$ obtained a score equal to or above the median value.

Among the variables which increased the possibility of getting a low score from the Knowledge and Attitude Index were the advanced age (2.7 times), not being married (35.7 times), not getting formal education (30.1 times), living in a non-crowded household (2.1 times), and low income ( $\leq 2000$ Turkish liras per month equal to $\leq \$ 357$ according to April 2019 exchange rates) (3.1 times) (Table 3).

\section{DISCUSSION}

This community-based study with a large sample is the first study conducted in Turkey to determine farmers' knowledge of and attitudes towards pesticide use, and related factors, and to provide decisionmakers with data on this issue. The mean scores the participants obtained from the Knowledge and Attitude Index was $12.8 \pm 2.8$ (min: 4, max: 19) and

Table 2. The participating farmers' knowledge and attitudes towards pesticide use

\begin{tabular}{|c|c|c|c|c|c|c|}
\hline & \multicolumn{2}{|c|}{ Yes } & \multicolumn{2}{|c|}{ No } & \multicolumn{2}{|c|}{ I do not know } \\
\hline & $\mathrm{n}$ & $\%$ & $\mathrm{n}$ & $\%$ & $\mathrm{n}$ & $\%$ \\
\hline Pesticides increase productivity in agriculture & 1822 & 86.8 & 278 & 13.2 & 0 & - \\
\hline Pesticides are harmful to human health & 462 & 22.0 & 864 & 41.1 & 774 & 36.9 \\
\hline Pesticides are harmful to the environment & 1427 & 68.0 & 19 & 0.9 & 654 & 31.1 \\
\hline Pesticides can leave residue in vegetables and fruit & 1368 & 65.1 & 658 & 31.3 & 74 & 3.5 \\
\hline $\begin{array}{l}\text { Pesticides should only be used for the product for which it is } \\
\text { licensed. }\end{array}$ & 903 & 43.0 & 562 & 26.8 & 635 & 30.2 \\
\hline $\begin{array}{l}\text { Pesticide selection can be made (pesticides to be used can be } \\
\text { selected) according to the recommendation by a friend /neighbor / } \\
\text { relative }\end{array}$ & 1375 & 65.5 & 408 & 19.4 & 317 & 15.1 \\
\hline Cheaper pesticides should be preferred. & 1742 & 83.0 & 303 & 14.4 & 55 & 2.6 \\
\hline Pesticide selection should be based on the disease / pest & 1252 & 59.6 & 491 & 23.4 & 357 & 17.0 \\
\hline $\begin{array}{l}\text { The dosage of the pesticide should be adjusted as stated on the } \\
\text { information label on the package of the pesticide }\end{array}$ & 1456 & 69.3 & 300 & 14.3 & 344 & 16.4 \\
\hline $\begin{array}{l}\text { If necessary, more than the recommended dose of pesticide can be } \\
\text { sprayed }\end{array}$ & 1390 & 66.2 & 187 & 8.9 & 523 & 24.9 \\
\hline Spraying should be performed just before harvesting & 815 & 38.8 & 892 & 42.5 & 393 & 18.7 \\
\hline Spraying should be done out of noon hours & 699 & 33.3 & 1319 & 62.8 & 82 & 3.9 \\
\hline Gloves should be worn during spraying & 1423 & 67.8 & 548 & 26.1 & 129 & 6.1 \\
\hline A mask should be worn during spraying & 677 & 32.2 & 886 & 42.2 & 537 & 25.6 \\
\hline Special overalls should be worn during spraying & 809 & 38.5 & 503 & 24.0 & 788 & 37.5 \\
\hline Boots should be worn during spraying & 1077 & 51.3 & 531 & 25.3 & 492 & 23.4 \\
\hline One can smoke during spraying & 900 & 42.9 & 788 & 37.5 & 412 & 19.6 \\
\hline Hands should be washed after spraying & 1442 & 68.7 & 129 & 6.1 & 529 & 25.2 \\
\hline One should take a shower after spraying & 1377 & 65.6 & 545 & 26.0 & 178 & 8.5 \\
\hline Empty pesticide containers should be buried in the ground & 1303 & 62.0 & 641 & 30.5 & 156 & 7.4 \\
\hline Empty pesticide containers might be left in the environment & 1216 & 57.9 & 677 & 32.2 & 207 & 9.9 \\
\hline $\begin{array}{l}\text { Empty pesticide containers should be put in a plastic bag and then } \\
\text { in an outdoor garbage can }\end{array}$ & 737 & 35.1 & 1121 & 53.4 & 242 & 11.5 \\
\hline
\end{tabular}


Table 3. Correlation between the farmers' Knowledge and Attitude Index scores and their sociodemographic characteristics

\begin{tabular}{|c|c|c|c|c|c|c|c|}
\hline \multirow{3}{*}{ Variables } & \multicolumn{2}{|c|}{$\begin{array}{l}\text { Knowledge and Attitude } \\
\text { Index score }\end{array}$} & \multirow{2}{*}{\multicolumn{2}{|c|}{ Univariate analysis }} & \multirow{2}{*}{\multicolumn{3}{|c|}{$\begin{array}{c}\text { Multivariate } \\
\text { Logistic regression }\end{array}$}} \\
\hline & \multirow{2}{*}{$\begin{array}{c}\text { low } \\
\mathrm{n}(\% *)\end{array}$} & \multirow{2}{*}{$\begin{array}{l}\text { high } \\
\mathrm{n}(\% *)\end{array}$} & & & & & \\
\hline & & & $\mathrm{X}^{2}$ & $\mathrm{p}$ & OR & $\mathrm{p}$ & $\% 95 \mathrm{GA}$ \\
\hline \multicolumn{8}{|l|}{ Place of residence } \\
\hline District center & $203(45.0)$ & $248(55.0)$ & & & & & \\
\hline Village & $837(50.8)$ & $812(49.2)$ & 4.679 & 0.031 & 0.9 & 0.587 & $0.7-1.1$ \\
\hline \multicolumn{8}{|l|}{ Age } \\
\hline$\leq 54$ (ref) & $665(41.7)$ & $928(58.3)$ & & & & & \\
\hline$\geq 55$ & $375(74.0)$ & $132(26.0)$ & 159.712 & 0.001 & 2.7 & 0.001 & $1.9-3.8$ \\
\hline \multicolumn{8}{|l|}{ Marital status } \\
\hline Married (ref) & $970(47.8)$ & $1058(52.2)$ & & & & & \\
\hline Single & $70(97.2)$ & $2(2.8)$ & 67.856 & 0.001 & 35.7 & 0.001 & $8.6-147.4$ \\
\hline \multicolumn{8}{|l|}{ Educational status } \\
\hline No formal education & $293(98.3)$ & $5(1.7)$ & 330.819 & 0.001 & 30.1 & 0.001 & $11.9-76.2$ \\
\hline $\begin{array}{l}\text { Primary school and } \\
\text { above (ref) }\end{array}$ & $747(41.5)$ & $1055(58.5)$ & & & & & \\
\hline \multicolumn{8}{|c|}{ The number of households } \\
\hline$\leq 4$ & $810(63.4)$ & $467(36.6)$ & 252.070 & 0.001 & 2.1 & 0.001 & $1.7-2.6$ \\
\hline$\geq 5$ (ref) & $230(27.9)$ & $593(72.1)$ & & & & & \\
\hline \multicolumn{8}{|c|}{ Income per month (USD)** } \\
\hline$\leq \$ 357$ & $963(54.5)$ & $803(45.5)$ & 111.322 & 0.001 & 3.1 & 0.001 & $2.2-4.4$ \\
\hline$>\$ 357$ (ref) & $77(23.1)$ & $257(76.9)$ & & & & & \\
\hline \multicolumn{8}{|c|}{ Total length of time spent in farming } \\
\hline$\leq 20$ years $($ ref $)$ & $477(40.5)$ & $702(59.5)$ & & & & & \\
\hline$>20$ years & $563(61.1)$ & $358(38.9)$ & 88.386 & 0.001 & 0.8 & 0.122 & $0.67-1.1$ \\
\hline
\end{tabular}

* Row percentage; OR: Odds Ratio

$* * \$ 1=5.74$ Turkish Liras according to April 2019 exchange rates.

the median value was 13 . Approximately half of the farmers' $(49.5 \%)$ score was lower than the median value. The variables which increased the possibility of getting a low score from the Knowledge and Attitude Index were advanced age, not being married, not getting formal education, living in a non-crowded household, and low income.

In the present study, the rate of the farmers who thought that pesticides were harmful to human health was $22 \%$ which was lower than that in the literature [12]. On the other hand, $68 \%$ of them thought that pesticides were harmful to the environment which was consistent with the literature $[12,32]$ and $69.3 \%$ stated that labels should be read, which was also consistent with the literature [23]. In the present study, the rate of the farmers who took a shower immediately after spraying was $65.6 \%$, which was slightly lower than that in the literature $[12,25]$. Consistent with the literature, two-thirds of the farmers in our study stated that the empty pesticide containers might be left in the environment [21, 28]. In our study, the rates of those who thought that protective clothing such as masks and special overalls should be worn during spraying were
$32.2 \%$ and $38.5 \%$ respectively. However, these rates ranged between $32.2 \%$ and $68.8 \%$ in the literature [4, $7,17,21,23,25,28]$.

In our study, the Knowledge and Attitude Index scores of the majority of the participating farmers were low. The review of studies in the literature indicated that the rate of the participants whose knowledge / attitude was sufficient ranged between 34\% and $85 \%[3,7,17,18,19,27,29]$. The results of our study are consistent with those of studies in the literature. However, the fact that knowledge / attitude levels were low in half of the farmers in the present study conducted in an agriculture intensive region located in the West of Turkey is an important issue. While knowledge / attitude levels of $33 \%(n=70)$ of the participating farmers in a study conducted by Derafsi et al. in a more developed region of Turkey, and $65.9 \%$ $(n=56)$ of the participating farmers in a study carried out by Saeed et al. in Pakistan were lower than were those of the participants in our study [7], in Thao et al.'s study carried out in the USA, $85 \%(n=28)$ of the participating farmers had sufficient knowledge / attitude levels. These differences may be due to 
differences between the participants' educational levels and cultural backgrounds, and regions they live in [29].

In the present study, advanced age increased the possibility of getting a low score from the Knowledge and Attitude Index 2.7 times. The results of Sharafi et al.'s [28] study conducted with 311 farmers in Iran. On the other hand, in Derafshi et al.'s study including 70 farmers, unlike the present study, as the age increased so did the level of knowledge/attitude, which is probably due to the fact that educational status of the farmers in Derafshi et al.'s study was higher and that no further analysis was performed [7].

In the present study, not getting formal education increased the possibility of getting a low score from the Knowledge and Attitude Index 30.1 times. Educational status is a factor which not only increases the level of knowledge/attitude regarding the reading of the labels on pesticides, understanding the instructions on how to use protective equipment, knowing the harmful effects of pesticide use $[19,20,27]$, but also reduces pesticide poisoning [26, 28, 29]. In Abollahzadeh et al.'s [2], Sharafi et al.'s [9] and Fuhriman et al.'s [28] studies, similar to our study, the knowledge/attitude levels of those with a high level of education were high.

In the present study, low income $(\leq 2000$ Turkish liras per month equal to $\leq \$ 357$ according to April 2019 exchange rates) increased the possibility of getting a low score from the Knowledge and Attitude Index 3.1 times. The lower the income level was the lower the participant's knowledge/attitude score was, which was consistent with that in the literature [18, 28], which caused those with low income to have inappropriate sanitation conditions [5] and to be exposed to pesticides more [7, 13].

In the present study, being single increased the possibility of getting a low score from the Knowledge and Attitude Index 2.1 times, which was consistent with the results of several studies in the literature. This might be due to the fact that farmers who were single or lived with a small number of people did not care about the potential effects of pesticides [11] and that their perception of risk was low [24]. On the other hand, contrary to the finding of our study, in Muleme et al.'s study with a sample size of 167 people, marital status and the number of people living in the household did not affect the knowledge and attitude score [18]. This difference between the studies probably stemmed from the differences between the characteristics and cultural backgrounds of the study groups $[7,33]$.

\section{CONCLUSIONS}

The most noteworthy result of our study is that although it was conducted in a region in the west of
Turkey, where people's education is higher, about half of the participating farmers' knowledge and attitude levels were inadequate. The mean scores the participants obtained from the Knowledge and Attitude Index was $12.8 \pm 2.8$ (min: 4, max: 19) and the median was 13 .

Among the factors which caused the participants' mean Knowledge and Attitude Index score to be lower than the median value was advanced age, not being married not getting formal education, living in a noncrowded household, and low-income level. Given the participants' mean knowledge/attitude score was lower, it is recommended that farmers should be trained on harmful effects of pesticides on human health and disposal of hazardous pesticide-related waste and empty containers, and that they should be informed where they can receive information on this issue. They should also be taught about the importance of the use of protective equipment because the participating farmers' tendency to use protective equipment was low. Moreover, public health interventions for farmers should be planned, and training programs for the Pesticide Management Process should be implemented.

\section{Financial support}

This study was supported by Balikesir University Scientific Research Projects Unit under grant Number: 2018/169.

\section{Conflict of interest}

The authors have no potential conflict of interest.

\section{REFERENCES}

1. Abadi B. The determinants of cucumber farmers' pesticide use behavior in central Iran: Implications for the pesticide use management. Journal of cleaner production. 2018; 205:1069-81. https://doi.org/10.1016/j. jclepro.2018.09.147

2. Abdollahzadeh $G$, Sharifzadeh MS, Damalas CA. Motivations for adopting biological control among Iranian rice farmers. Crop Protection. 2016; 80:42-50. https://doi.org/10.1016/j.cropro.2015.10.021

3. Bagheri A, Emami N, Damalas CA, Allahyari MS. Farmers' knowledge, attitudes, and perceptions of pesticide use in apple farms of northern Iran: impact on safety behavior. Environmental Science and Pollution Research. 2019;26(9):9343-51. https://doi.org/10.1007/ s11356-019-04330-y

4. Bondori A, Bagheri A, Damalas CA, Allahyari MS. Use of personal protective equipment towards pesticide exposure: Farmers' attitudes and determinants of behavior. Science of the total environment. 2018; 639:1156-63. https://doi.org/10.1016/j. scitotenv.2018.05.203 
5. Capellesso AJ, Cazella AA, Schmitt Filho AL, Farley $J$, Martins DA. Economic and environmental impacts of production intensification in agriculture: comparing transgenic, conventional, and agroecological maize crops. Agroecology and Sustainable Food Systems. 2016;40(3):215-36. https://doi.org/10.1080/21683565.201 5.1128508

6. Chowdhury FR, Dewan G, Verma VR, Knipe DW, Isha IT, Faiz MA, et al. Bans of WHO class I pesticides in Bangladesh-suicide prevention without hampering agricultural output. International journal of epidemiology. 2018;47(1):175-84. https://doi. org/10.1093/ije/dyx157

7. Derafshi M, Black C, Agnew R. Pesticide knowledge, attitudes, and clothing practices of Turkish farmers. Environ Management Sustainable Develop. 2017; 6:14967. https://doi.org/10.5296/emsd.v6i1.10271

8. Farahat TM, Shaheen HM, Sanad ZF, Frag $N A$. Knowledge, attitudes, and practices of organophosphorus pesticide exposure among women affiliated to the Manshat Sultan Family Health Center (rural area) in Menoufia governorate: an intervention study. Menoufia medical journal. 2016;29(1):115. https:// doi.org/10.4103/1110-2098.179000

9. Fuhrimann S, Winkler MS, Staudacher P, Weiss FT, Stamm C, Eggen RI, et al. Exposure to pesticides and health effects on farm owners and workers from conventional and organic agricultural farms in Costa Rica: protocol for a cross-sectional study. JMIR research protocols. 2019;8(1):e10914. https://doi. org/10.2196/10914

10. General Directorate of Agricultural Enterprises. Land regulation 2020 [25.02.2020]. Available from: https:// www.tigem.gov.tr/Sayfalar/Detay/6006f575-91db4fbb-b7ee-6ee037a63b50.

11. Gustafsson K. Made in conflict. Local residents' construction of a local environmental problem. Local Environment. 2011;16(7):655-70. https://doi.org/10.1080 /13549839.2011.589431

12.Jallow MF, Awadh DG, Albaho MS, Devi VY, Thomas $B M$. Pesticide knowledge and safety practices among farm workers in Kuwait: Results of a survey. International journal of environmental research and public health. 2017;14(4):340. https://doi.org/10.3390/ ijerph14040340

13.Jin J, Wang W, He R, Gong H. Pesticide use and risk perceptions among small-scale farmers in Anqiu County, China. International journal of environmental research and public health. 2017;14(1):29. https://doi. org/10.3390/ijerph14010029

14. Kalıpcı E, Özdemir C, Öztaş H. Çiftçilerin pestisit kullanımı ile ilgili eğitim ve bilgi düzeyi ile çevresel duyarlılıklarının araştırılması. TÜBAV Bilim Dergisi. 2011;4(3):179-87.

15. Karunarathne A, Gunnell D, Konradsen F, Eddleston $M$. How many premature deaths from pesticide suicide have occurred since the agricultural Green Revolution? Clinical toxicology. 2020;58(4):227-32. https://doi.org/1 $0.1080 / 15563650.2019 .1662433$
16. Li Z . The use of a disability-adjusted life-year (DALY) metric to measure human health damage resulting from pesticide maximum legal exposures. Science of The Total Environment. 2018; 639:438-56. https://doi. org/10.1016/j.scitotenv.2018.05.148

17. Mohamed AO, Mater AA, Hammad A, Ishag A, Abdelbagi AO, Eldein AM, et al. Knowledge, Attitudes and Practices of Pesticide's Sprayers towards Pesticides Use and Handling in Greenhouse Farms, Sudan. International Journal of Management and Commerce Innovations. 2018;6(2):840-50. https://doi.org/10.1093/ occmed/52.6.311

18. Muleme J, Kankya C, Ssempebwa JC, Mazeri S, Muwonge A. A Framework for integrating Qualitative and Quantitative Data in Knowledge, attitude, and Practice studies: a case study of Pesticide Usage in eastern Uganda. Frontiers in public health. 2017; 5:318. https://doi.org/10.3389/fpubh.2017.00318

19. NguyeN TM, Le NTT, HaVukaiNeN J, HaNNaway $D B$. Pesticide use in vegetable production: A survey of Vietnamese farmers' knowledge. Plant Protection Science. 2018;54(4):203-14. https://oi. org/10.17221/69/2017-pps

20.Nigatu AW, Bråtveit M, Moen BE. Self-reported acute pesticide intoxications in Ethiopia. BMC public health. 2016;16(1):575. https://doi.org/10.1186/s12889-016-31965

21. Öztaş $D$, Kurt $B, \operatorname{Koç} A$, Akbaba $M$, Ilter $H$. Knowledge Level, Attitude, and Behaviors of Farmers in Çukurova Region regarding the Use of Pesticides. BioMed research international. 2018;2018. https://doi. org/10.1155/2018/6146509

22.Riccò M, Vezzosi L, Gualerzi G. Health and safety of pesticide applicators in a high income agricultural setting: a knowledge, attitude, practice, and toxicity study from North-Eastern Italy. Journal of preventive medicine and hygiene. 2018;59(3): E200. 10.15167/24214248/jpmh2018.59.3.934

23. Rijal JP, Regmi R, Ghimire R, Puri KD, Gyawaly S, Poudel $S$. Farmers' knowledge on pesticide safety and pest management practices: a case study of vegetable growers in Chitwan, Nepal. Agriculture. 2018;8(1):16. https://doi.org/10.3390/agriculture8010016

24.Ríos-González A, Jansen K, Sánchez-Pérez HJ. Pesticide risk perceptions and the differences between farmers and extensionists: Towards a knowledge-incontext model. Environmental research. 2013; 124:4353. https://doi.org/10.1016/j.envres.2013.03.006

25.Rostami F, Afshari M, Rostami-Moez M, Assari MJ, Soltanian $A R$. Knowledge, attitude, and practice of pesticides use among agricultural workers. Indian journal of occupational and environmental medicine. 2019;23(1):42. https://doi.org/10.4103/ijoem. IJOEM_153_18

26. Saeed $\bar{M} F$, Shaheen M, Ahmad I, Zakir A, Nadeem $M$, Chishti $A A$, et al. Pesticide exposure in the local community of Vehari District in Pakistan: an assessment of knowledge and residues in human blood. Science of the Total Environment. 2017; 587:137-44. https://doi. org/10.1016/j.scitotenv.2017.02.086 
27. Santos MJ. Training networks for adapting to the agricultural system: latino blueberry farmers in the United States. International Journal of Agricultural Extension. 2015;3(1):13-23.

28. Sharafi K, Pirsaheb M, Maleki S, Arfaeinia H, Karimyan $K$, Moradi $M$, et al. Knowledge, attitude and practices of farmers about pesticide use, risks, and wastes; a crosssectional study (Kermanshah, Iran). Science of the total environment. 2018; 645:509-17. https://doi.org/10.1016/j. scitotenv.2018.07.132

29. Thao C, Burke N, Ha S, Joyce A. Pesticide Knowledge, Attitudes, and Practices Among Small-Scale Hmong Farmers in the San Joaquin Valley of California. Journal of Integrated Pest Management. 2019;10(1):32. https:// doi.org/10.1093/jipm/pmz030

30.Turkish Statistical Institute. Labor Force Statistics 2017 [06.12.2019]. Available from: http://tuik.gov.tr/ PreHaberBultenleri.do?id=24632.
31. World Health Organization. Food and Agriculture Organization of the United Nations (FAO). IPCS International Programme on Chemical Safety. INCHEM, Chemical Safety Information from Intergovernmental Organization. 2015. 2018.

32. Yilmaz H. Analysis in terms of environmental awareness of farmers' decisions and attitudes in pesticide use: the case of Turkey. Bulg Chem Commun. 2015; 47:771-5.

33. Zhang $L, L i X$. The impact of traditional culture on farmers' moral hazard behavior in crop production: Evidence from China. Sustainability. 2016;8(7):643. https://doi.org/10.3390/su8070643

Received: 16.05 .2020

Accepted: 15.06 .2020 